\title{
Patient-specific instrumentation does not improve tibial component coronal alignment for medial UKA compared to conventional instrumentation
}

\author{
Houssam Kalache ${ }^{1}$, Jacobus H. Müller ${ }^{2}$, Mo Saffarini ${ }^{2^{*}}$ (D) and Evrard Gancel ${ }^{1}$
}

\begin{abstract}
Background: Patient-specific instrumentation (PSI) may potentially improve unicompartmental knee arthroplasty (UKA) implant positioning and alignment. The purpose of this study was to compare early radiographic coronal alignment of medial UKA performed using PSI versus conventional instrumentation (CI) for tibial resections.

Methods: A consecutive series of 47 knees (47 patients) received medial UKA, with the tibial resections performed using $\mathrm{Cl}$ (first 22 knees) or PSI (next 25 knees), while femoral resections were performed with $\mathrm{Cl}$ in both groups. The target mechanical medial proximal tibial angle (MMPTA) was $87^{\circ} \pm 3^{\circ}$, and the target hip-knee-ankle (HKA) angle was $177^{\circ} \pm 2^{\circ}$. The postoperative mMPTA and HKA were evaluated from postoperative radiographs at a follow-up of 2 months.

Results: Differences in postoperative mMPTA $(p=0.509)$ and HKA $(p=0.298)$ between the two groups were not statistically significant. For the mMPTA target, $24 \%$ of knees in the PSI group $\left(85.6^{\circ} \pm 2.1^{\circ}\right)$ and $32 \%$ of the $\mathrm{Cl}$ group $\left(85.0^{\circ} \pm 3.6^{\circ}\right)$ were outliers. For the HKA target, $44 \%$ of knees in the PSI group $\left(176.3^{\circ} \pm 2.8^{\circ}\right)$ and $18 \%$ of the Cl group $\left(177.1^{\circ} \pm 2.3^{\circ}\right)$ were outliers. Considering the two criteria simultaneously, $60 \%$ of knees in the PSI group and $45 \%$ of knees in the $\mathrm{Cl}$ group were outside the target zone $(p=0.324)$, whereas $28 \%$ of knees in the PSI group and $41 \%$ of knees in the $\mathrm{Cl}$ group were outside the target zone by more than $1^{\circ}(p=0.357)$.

Conclusions: The results of the present study revealed no statistically significant difference in radiographic coronal alignment of UKA performed using PSI versus CI for tibial resections.
\end{abstract}

Keywords: UKA, PSI, Conventional instrumentation, HKA angle, mMPTA

\section{Background}

Unicompartmental knee arthroplasty (UKA) was introduced by Marmor [1] in the 1970s as a less invasive treatment than total knee arthroplasty (TKA) for unicompartmental tibiofemoral arthritis. Its main benefits are bone-sparing cuts and preservation of the cruciate ligaments [2], which enable restoration of close-to-

* Correspondence: journals@resurg.eu

${ }^{2}$ ReSurg S.A, Rue Saint-Jean 22, 1260 Nyon, Switzerland

Full list of author information is available at the end of the article normal native biomechanics [3], particularly for knees with medial compartment arthritis $[4,5]$.

Advances in prosthesis design, surgical techniques and patient selection have led to improved outcomes and survival of UKA [6], but national registries still indicate inferior long-term survival compared to TKA [7, 8], mainly due to the progression of arthritis to adjacent compartments [9-11]. Several authors observed prosthetic malalignment to be a principal risk factor for the progression of arthritis and early failure [10, 12-14]. It is worth noting, however, that UKA revision rates tend to decrease with surgeon volume or experience [15], hence 
the recommendations that surgeons offering UKA should perform an annual minimum of 11 to 23 knees $[7,16,17]$.

Patient-specific instrumentation (PSI) was introduced to improve implant positioning and alignment $[13,18]$, notably to help less experienced surgeons achieve improved clinical and radiographic outcomes [17]. While some studies revealed that PSI improves accuracy of alignment for both TKA $[19,20]$ and UKA [21, 22], the differences are often insignificant [23]. Conversely, a recent randomized controlled trial reported decreased accuracy in UKA tibial alignment when using patientspecific tibial cutting guides, with deeper tibial resections, compared to conventional instrumentation [24]. Therefore, uncertainty remains on whether PSI yields more accurate coronal alignment compared to conventional instrumentation (CI). The purpose of this study was therefore to compare early radiographic coronal alignment of UKA performed using PSI versus CI for tibial resections. The hypothesis was that both types of instrumentation would render equivalent early radiographic coronal alignment.

\section{Material and methods \\ Patients}

A consecutive series of 47 knees (47 patients) received medial UKA using either CI or PSI to perform tibial resections over two consecutive years by the senior surgeon (EG) at the same center. Indications for surgery were localized medial tibiofemoral osteoarthritis (Ahlbäck grade $\geq 2$ ), with medial tibiofemoral pain, partial or complete intra-articular varus deformity $<10^{\circ}$, and extension deficit $\leq 5^{\circ}$. Tibial resections were performed using $\mathrm{CI}$ in the first 22 knees and PSI in the next 25 knees.

\section{Patient consent}

All patients provided informed consent for the participation in the study and the use of their data and images for research purposes.

\section{Preoperative planning}

Patients scheduled for UKA using PSI for the tibial resections had a preoperative Computed Tomography (CT) scan of the affected knee, with additional cross

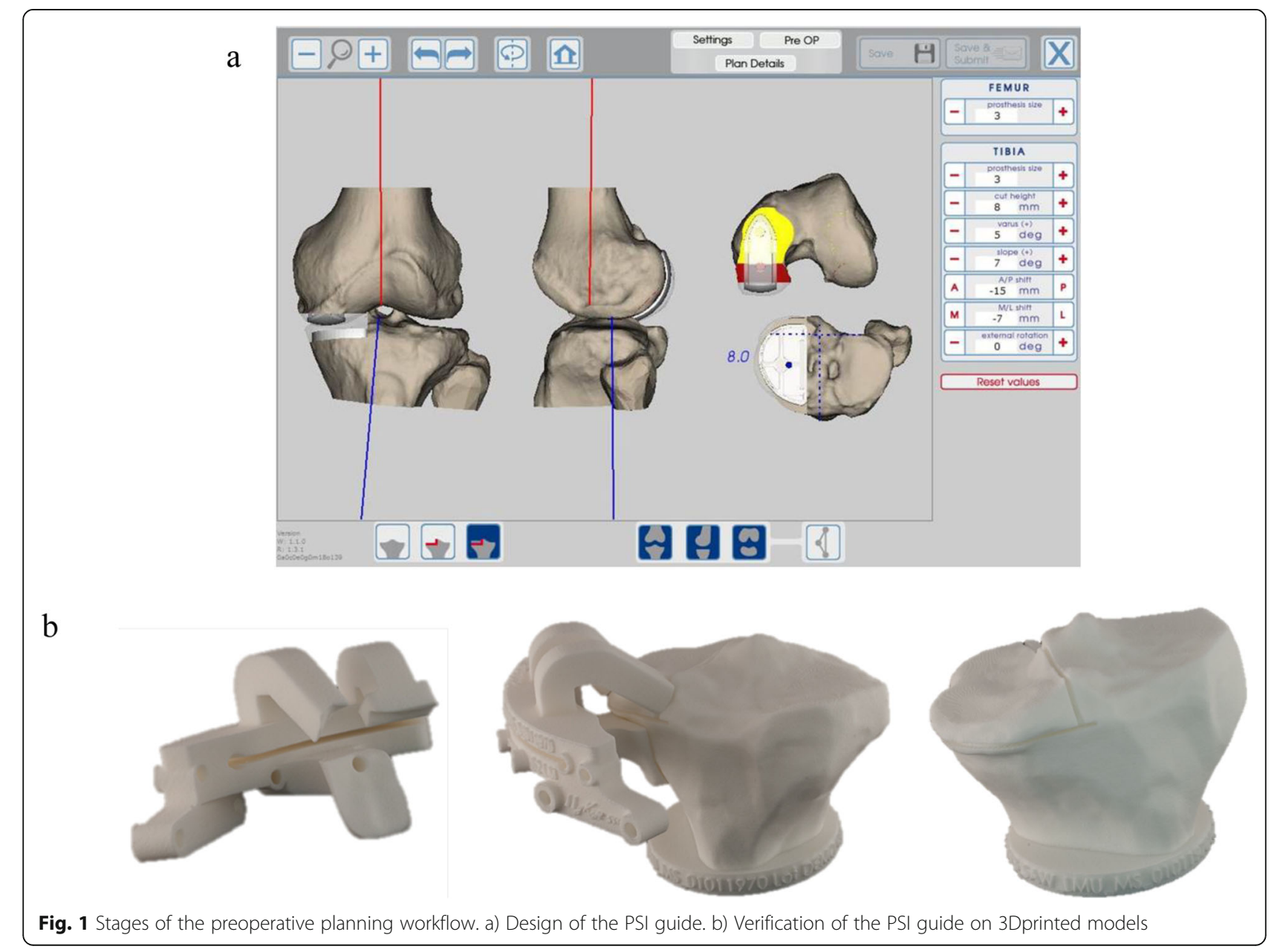


sections through the hip and ankle to determine the Hip-Knee-Ankle (HKA) angle. The tibial resection PSI guides were based on the surgical guidelines which aimed for a tibial resection of $6 \mathrm{~mm}$, mechanical medial proximal tibial angle (mMPTA) of $87^{\circ} \pm 3^{\circ}$ and HKA angle of $177^{\circ} \pm 2^{\circ}$ (Fig. 1) [10]. The tolerance of up to $3^{\circ}$ deviation was allowed to leave some residual varus in cases with greater deformity [2].

\section{Surgical technique}

All patients received a fixed bearing UKA (MyKnee UNI\#, Medacta, Castel San Pietro, Switzerland) following a standardized surgical technique with a pneumatic tourniquet. A minimally invasive medial parapatellar incision was made extending from the superior pole of the patella to $3 \mathrm{~cm}$ below the joint space. The PSI cutting guide was fixed with three pins to the proximal tibia, with the resection level measured from the deepest point on the medial tibial plateau (Fig. 2). Using an oscillating saw, the sagittal cut was performed first, followed by the axial cut, before the tibial insert size was validated. The resection level was systematically measured to ensure consistency with the preoperative plan of $6 \mathrm{~mm}$. In the CI group, the tibial cut was performed using an extramedullary guide, aiming for a resection level of 4 or $6 \mathrm{~mm}$ (depending on the amount of cartilage wear), mMPTA of $87^{\circ} \pm 3^{\circ}$ and HKA angle of $177^{\circ} \pm 2^{\circ}$.

In both groups, the distal and posterior femoral resections were performed next by using a dependent-cut guide to determine the distance from the tibial cut. The aim was to achieve an HKA angle target of $175^{\circ}$ to $179^{\circ}$, and a varus-valgus laxity of 1 to $2 \mathrm{~mm}$ both in flexion and in extension. Alignment was verified for both groups using an extramedullary guide. After verification of component sizes with trials, the UKA components were cemented in place (Palacos $R+G$, Zimmer, Wehrheim,
Germany). Tourniquet time was recorded for both groups.

\section{Radiographic assessment}

For both groups, frontal, sagittal and HKA radiographs were obtained preoperatively and at 2 months follow-up to measure the HKA angle and mMPTA.

\section{Statistical analysis}

Descriptive statistics were used to summarize the data and Shapiro-Wilk tests were used to assess the normality of distribution. For non-Gaussian quantitative data, differences between groups were evaluated using the Wilcoxon rank sum test (Mann Whitney $U$ test), and a Fisher's exact test was used to compare discrete quantitative variables. Considering the findings of Kerens et al. [25] who reported MMPTA to have a standard deviation of $3.6^{\circ}$, the required number of subjects was 44 (22 in each group) to achieve a power of $80 \%$ at a $5 \%$ level of significance. Statistical analyses were performed using $\mathrm{R}$ version 3.4.2. (R Foundation for Statistical Computing, Vienna, Austria). A $p$-value $<0.05$ was considered statistically significant.

\section{Results}

The mean age, BMI and tourniquet time were similar between the two groups, but there were significantly $(p=0.002)$ less women in the PSI group $(n=6(28 \%))$ compared with the CI group $(n=15(68 \%))$ (Table 1$)$.

Preoperative mMPTA was significantly $(p<0.012)$ smaller in the PSI group $\left(83.1^{\circ} \pm 2.0^{\circ}\right)$ compared with the CI group $\left(84.7^{\circ} \pm 2.0^{\circ}\right)$, but the postoperative mMPTA was similar between the two groups (Table 1). It is worth noting that the net change in MMPTA was significantly $(p=0.045)$ greater in the PSI group $\left(2.4^{\circ} \pm 2.6^{\circ}\right)$ compared with the CI group $\left(0.3^{\circ} \pm 4.1^{\circ}\right)$. The pre- and
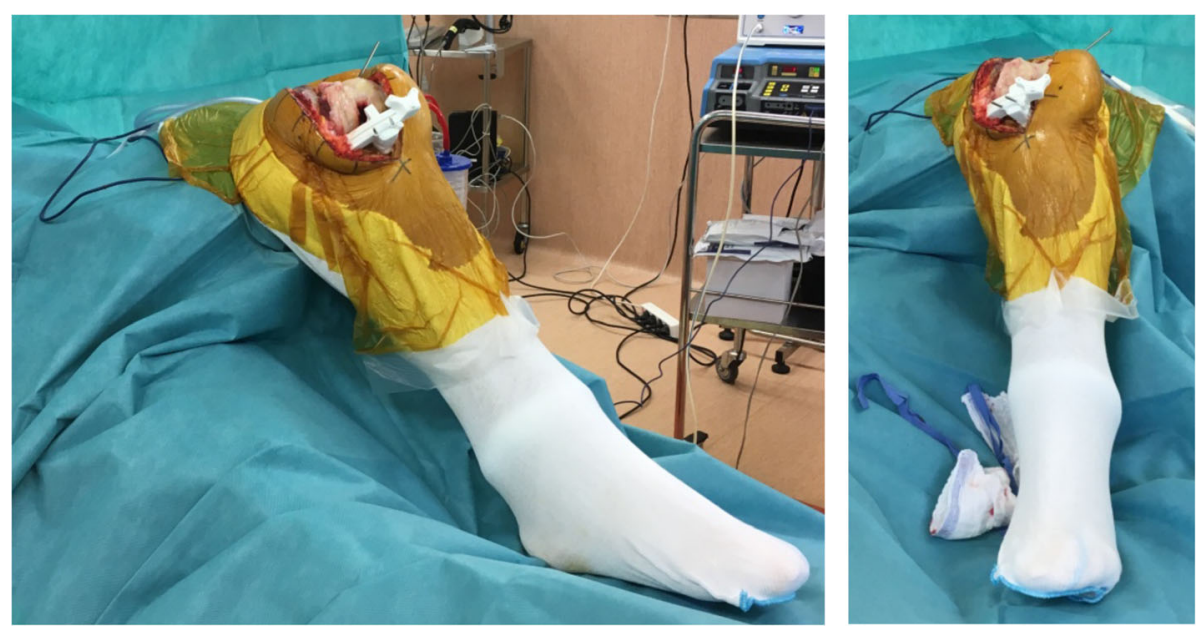

Fig. 2 Fixation of the tibial PSI cutting guide 
Table 1 Comparison of UKA using PSI versus using conventional instrumentation for tibial resections

\begin{tabular}{|c|c|c|c|c|c|}
\hline & \multicolumn{2}{|l|}{ PSI $(n=25)$} & \multicolumn{2}{|c|}{ Conventional $(n=22)$} & \multirow[b]{2}{*}{$p$ value } \\
\hline & $\begin{array}{l}\text { mean } \pm S D \\
\mathrm{n}(\%)\end{array}$ & $(\min -\max )$ & $\begin{array}{l}\text { mean } \pm S D \\
\mathrm{n}(\%)\end{array}$ & $(\min -\max )$ & \\
\hline \multicolumn{6}{|l|}{ Patient demographics } \\
\hline Age (years) & $65.1 \pm 9.2$ & $(46-86)$ & $70.5 \pm 9.2$ & $(52-85)$ & 0.050 \\
\hline BMI $\left(\mathrm{kg} / \mathrm{m}^{2}\right)$ & $27.3 \pm 2.9$ & $(21.3-32.2)$ & $26.4 \pm 3.6$ & $(21-33)$ & 0.365 \\
\hline Women & $6(24 \%)$ & & $15(68 \%)$ & & 0.002 \\
\hline Right knee & $15(60 \%)$ & & $12(55 \%)$ & & 0.709 \\
\hline \multicolumn{6}{|c|}{ Intraoperative measurements } \\
\hline Tourniquet time (min) & $58 \pm 6$ & $(45-75)$ & $58 \pm 9$ & $(50-90)$ & 0.55 \\
\hline \multicolumn{6}{|l|}{ Coronal alignment } \\
\hline \multicolumn{6}{|l|}{ HKA angle (deg) } \\
\hline Preoperative & $173.8 \pm 2.9$ & $(167-178)$ & $173.6 \pm 3.0$ & $(169-181)$ & 0.844 \\
\hline Postoperative & $176.3 \pm 2.8$ & $(170-183)$ & $177.1 \pm 2.3$ & $(171-181)$ & 0.298 \\
\hline Net change & $2.5 \pm 1.5$ & $(-1-5)$ & $3.4 \pm 2.4$ & $(-4-6)$ & 0.114 \\
\hline \multicolumn{6}{|l|}{ mMPTA (deg) } \\
\hline Preoperative & $83.1 \pm 2.0$ & $(80-87)$ & $84.7 \pm 2.0$ & $(81-88)$ & 0.012 \\
\hline Postoperative & $85.6 \pm 2.1$ & $(80-89)$ & $85.0 \pm 3.6$ & $(78-92)$ & 0.509 \\
\hline Net change & $2.4 \pm 2.6$ & $(-2-7)$ & $0.3 \pm 4.1$ & $(-7-7)$ & 0.045 \\
\hline
\end{tabular}

Abbreviations: PSI patient specific instruments, BMI body mass index, HKA hip-knee-ankle, mMPTA mechanical medial proximal tibial angle, min minutes, deg degrees

post-operative HKA angles were similar between the two groups.

Considering the criteria for coronal alignment of mMPTA between $87^{\circ} \pm 3^{\circ}, 24 \%$ of knees in the PSI group and $32 \%$ of the $\mathrm{CI}$ group were strictly outliers $(p=0.554)$, while only $8 \%$ of knees in the PSI group and 27\% of the CI group were outliers by more than $1^{\circ}(p=0.083)$. Considering the criteria for HKA angle between $177^{\circ} \pm 2^{\circ}, 44 \%$ of knees in the PSI group and $18 \%$ of the CI group were strictly outliers $(p=0.061)$, while only $24 \%$ of knees in the PSI group and $18 \%$ of the CI group were outliers by more than $1^{\circ}(p=0.630)$. Considering the two criteria simultaneously (Fig. 3), 60\% of knees in the PSI group and $45 \%$ of knees in the CI group were strictly outside the target zone $(p=0.324)$, while $28 \%$ of knees in the PSI group and $41 \%$ of knees in the CI group were outside the target zone by more than $1^{\circ}(p=0.357)$. The differences in proportions of outliers were not statistically significant between the two groups.

\section{Discussion}

The main finding of this study was that the difference in radiographic coronal alignment of UKA performed using PSI versus CI for tibial resections is not statistically significant. This finding therefore supports the hypothesis that PSI does not improve tibial component coronal alignment for UKA compared to CI. The clinical relevance of the findings was that, compared to $\mathrm{CI}$, PSI yielded less outliers from the target mMPTA but more outliers from the target HKA angle, although the differences were not statistically significant. When the two criteria were considered simultaneously, the proportion of absolute outliers was greater in the PSI group, but the proportion of outliers by more than $1^{\circ}$ was greater in the CI group.

Previous studies $[13,18]$ have demonstrated superior accuracy for implant positioning in UKA using PSI compared to CI. In the present study, accuracy in coronal alignment of UKA was equivalent using PSI versus CI. This conflicting finding might be due to the experience level of the senior surgeon, who performs 40 UKAs annually, which is considerably greater than the range of 11 to 23 annually, as suggested by guidelines $[1,7,16]$. Moreover, Sanz-Ruiz et al. [17] highlighted the true value of PSI to be improvement of clinical and radiographic outcomes of UKA by inexperienced surgeons, during their learning curve.

The reported radiographic outcomes for MMPTA and HKA angle of the present study compare well to previous findings. In a prospective study, Kerens et al. [25] compared 30 UKAs using PSI to 30 UKAs using CI. The mMPTA was $89^{\circ}$ (range, $83^{\circ}$ to $93^{\circ}$ ) using PSI and $88^{\circ}$ (range, $80^{\circ}$ to $95^{\circ}$ ) using $\mathrm{CI}$, and HKA angle was $176^{\circ}$ (range, $168^{\circ}$ to $182^{\circ}$ ) using PSI and $176^{\circ}$ (range, $169^{\circ}$ to $182^{\circ}$ ) using CI. In randomized controlled trial, Ollivier et al. [26] compared 30 UKAs using PSI to 30 UKAs using CI. The mMPTA was $89^{\circ}$ (range, $88^{\circ}$ to $93^{\circ}$ ) using PSI and $89^{\circ}$ (range, $87^{\circ}$ to $92^{\circ}$ ) using CI, and HKA angle was $178^{\circ}$ (range, $176^{\circ}-182^{\circ}$ ) using PSI and $178^{\circ}$ (range, 


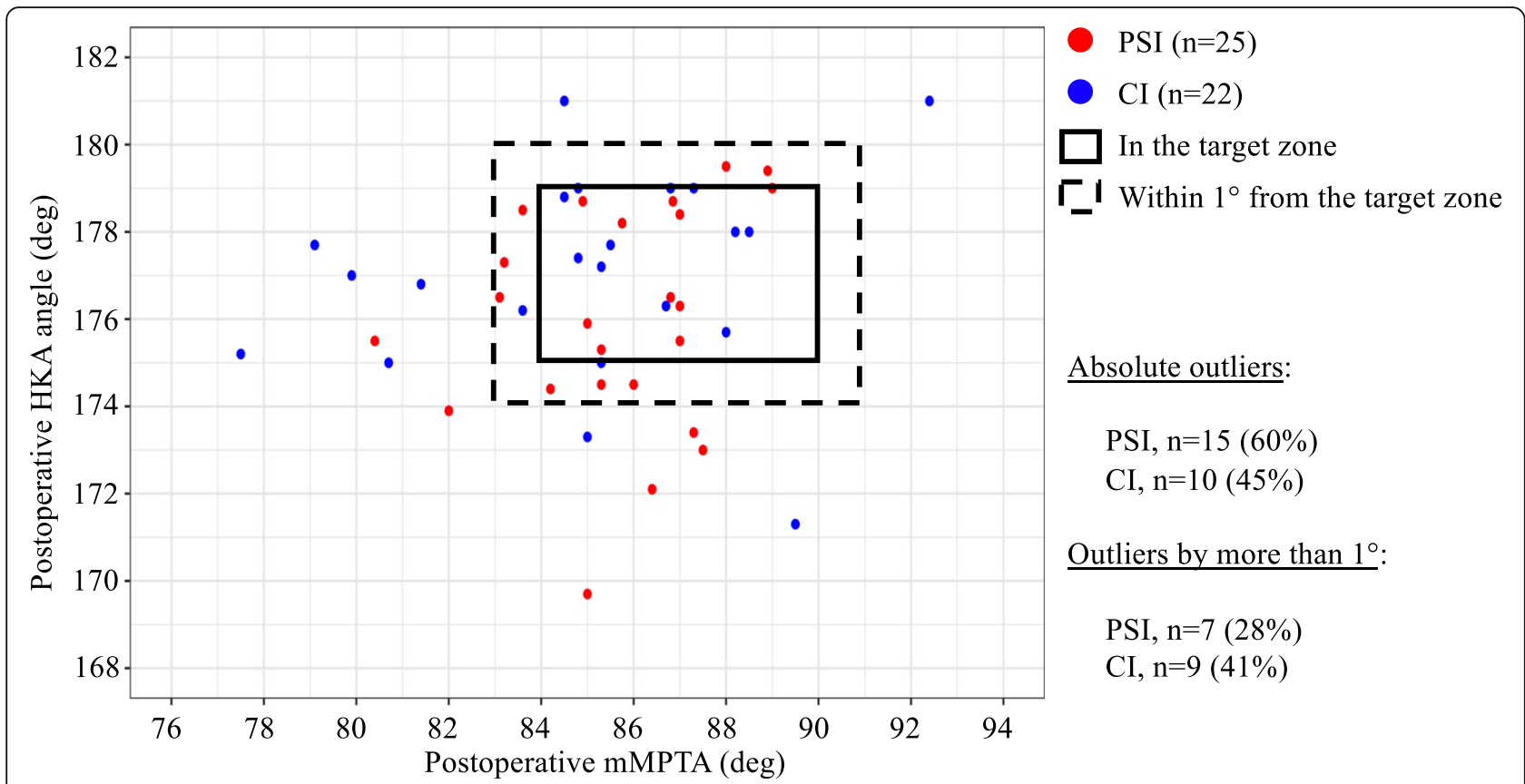

Fig. 3 Comparison of UKA using PSI versus conventional instrumentation for tibial component alignment to achieve the coronal alignment target zone

$175^{\circ}$ to $182^{\circ}$ ) using CI. Leenders et al. [27] published results of a continuous series of 129 UKAs using PSI, and reported mMPTA of $90.9^{\circ}$ (range, $81.4^{\circ}$ to $99.6^{\circ}$ ) and HKA angle of $176.4^{\circ} \pm 3.4^{\circ}$. In the present study, there were considerable proportions of outliers in both the PSI and CI group, though comparison to proportions reported in the literature is difficult due to differences in definitions of target zones.

Malpositioning of the tibial component in UKA increases the risk of component migration and loosening, leading to higher revision rates, especially in low volume surgical centres [28]. Assistive technologies like PSI and robotic surgery has the potential to improve component positioning, but it is unclear which technology is best suited to this task [29]. Recent findings suggest that, compared to UKA using CI, robot-assisted UKA grants improved restitution of the joint-line height, leads to lower alignment outliers and revision rates [30, 31]. Interestingly, a recent randomised control trial [29] revealed that PSI for tibial component positioning in UKA resulted in comparable accuracy to a robotic system. However, the use of PSI does not guarantee accurate tibial rotational alignment [32] and may lead to increased operating time, reduced accuracy and considerable costs [33]. The findings of the present study revealed comparable coronal alignment between PSI and CI, and therefore does not support the routine use of PSI for medial UKA.

These findings of the present study need to be interpreted with the following limitations in mind. First, this was a retrospective study without any randomization. However, the radiographs were systematically obtained as part of normal follow-up for UKA, and blinded before measurement of the radiographic outcomes. Second, preoperative MMPTA was statistically different between the two groups, but it was by random chance since CI was used on the first 22 knees and PSI on the next 25 knees. Moreover, although statistically significant, a mean difference of $1.6^{\circ}$ is not clinically relevant. Third, no clinical scores were recorded, and it is unclear if the radiographic outcomes are related to clinical outcomes. Fourth, the study might be underpowered due to the relatively small number of knees in the two groups. Fifth, radiographic measurements were obtained at 2 months follow-up, and some knees could still have residual stiffness with some amount of flexion contracture. This might affect the radiographic analysis and alter the measurements, although all patients followed the same rehabilitation protocol.

\section{Conclusion}

The results of the present study revealed no statistically significant difference in radiographic coronal alignment of UKA performed using PSI versus CI for tibial resections. In UKA performed by a high-volume surgeon, PSI did not improve tibial component alignment compared to CI. The choice of PSI versus CI requires careful consideration, especially for experienced surgeons, since the present study could not demonstrate any radiographic benefit. 


\section{Abbreviations}

PSI: Patient-specific instrumentation; UKA: Unicompartmental knee arthroplasty; Cl: Conventional instrumentation; mMPTA: Mechanical medial proximal tibial angle; HKA: Hip-knee-ankle; TKA: Total knee arthroplasty; $\mathrm{CT}$ : Computed tomography

\section{Authors' contributions}

HK study design, data collection and manuscript editing. JHM literature review, statistical analysis, interpretation of findings, figures and manuscript writing. MS interpretation of findings, figures, manuscript writing. EG study design, interpretation of findings and manuscript editing. All authors approved the final manuscript.

\section{Funding}

None.

\section{Availability of data and materials}

Not applicable.

\section{Ethics approval and consent to participate}

All patients provided informed consent for the participation in the study and the use of their data and images for research purposes.

\section{Competing interests}

The authors declare that they have no competing interests.

\section{Author details}

${ }^{1}$ Centre Hospitalier Privé Saint-Grégoire, 6 Boulevard de la Boutière, 35760 Saint-Grégoire, France. ${ }^{2}$ ReSurg S.A, Rue Saint-Jean 22, 1260 Nyon, Switzerland

Received: 19 March 2020 Accepted: 25 May 2020

Published online: 08 June 2020

\section{References}

1. Marmor L (1973) The modular knee. Clin Orthop Relat Res (94):242-248. https://doi.org/10.1097/00003086-197307000-00029

2. Franz A, Boese CK, Matthies A, Leffler J, Ries C (2019) Mid-term clinical outcome and reconstruction of posterior Tibial slope after UKA. J Knee Surg 32(5):468-474

3. Heyse TJ, El-Zayat BF, De Corte R, Chevalier $Y$, Scheys L, Innocenti B, FuchsWinkelmann S, Labey L (2014) UKA closely preserves natural knee kinematics in vitro. Knee Surg Sports Traumatol Arthrosc 22(8):1902-1910

4. Noticewala MS, Geller JA, Lee JH, Macaulay W (2012) Unicompartmental knee arthroplasty relieves pain and improves function more than total knee arthroplasty. J Arthroplast 27(8 Suppl):99-105

5. Panni AS, Vasso M, Cerciello S, Felici A (2012) Unicompartmental knee replacement provides early clinical and functional improvement stabilizing over time. Knee Surg Sports Traumatol Arthrosc 20(3):579-585

6. Parratte S, Ollivier M, Lunebourg A, Abdel MP, Argenson JN (2015) Longterm results of compartmental arthroplasties of the knee: long term results of partial knee arthroplasty. Bone Joint J 97-b (10 Suppl a):9-15

7. Baker P, Jameson S, Critchley R, Reed M, Gregg P, Deehan D (2013) Center and surgeon volume influence the revision rate following unicondylar knee replacement: an analysis of 23,400 medial cemented unicondylar knee replacements. J Bone Joint Surg Am 95(8):702-709

8. Niinimaki T, Eskelinen A, Makela K, Ohtonen P, Puhto AP, Remes V (2014) Unicompartmental knee arthroplasty survivorship is lower than TKA survivorship: a 27-year Finnish registry study. Clin Orthop Relat Res 472(5): 1496-1501

9. Deroche E, Batailler C, Lording T, Neyret P, Servien E, Lustig S (2019) High survival rate and very low Wear of lateral Unicompartmental Arthroplasty at long term: a case series of 54 cases at a mean follow-up of 17 years. J Arthroplast 34(6):1097-1104

10. Hernigou P, Deschamps G (2004) Alignment influences wear in the knee after medial unicompartmental arthroplasty. Clin Orthop Relat Res 12(423): 161-165. https://doi.org/10.1097/01.blo.0000128285.90459

11. Lustig S, Lording T, Frank F, Debette C, Servien E, Neyret P (2014) Progression of medial osteoarthritis and long term results of lateral unicompartmental arthroplasty: 10 to 18 year follow-up of 54 consecutive implants. Knee 21(Suppl 1):S26-S32
12. Epinette JA, Brunschweiler B, Mertl P, Mole D, Cazenave A (2012) Unicompartmental knee arthroplasty modes of failure: wear is not the main reason for failure: a multicentre study of 418 failed knees. Orthop Traumatol Surg Res 98(6 Suppl):S124-S130

13. Flury A, Hasler J, Dimitriou D, Antoniadis A, Finsterwald M, Helmy N (2019) Midterm clinical and radiographic outcomes of 115 consecutive patientspecific unicompartmental knee arthroplasties. Knee 26(4):889-896

14. Heyse TJ, Lipman JD, Imhauser CW, Tucker SM, Rajak Y, Westrich GH (2014) Accuracy of individualized custom Tibial cutting guides in UKA. HSS J 10(3): 260-265

15. Jones GG, Logishetty K, Clarke S, Collins R, Jaere M, Harris S, Cobb JP (2018) Do patient-specific instruments (PSI) for UKA allow non-expert surgeons to achieve the same saw cut accuracy as expert surgeons? Arch Orthop Trauma Surg 138(11):1601-1608

16. Badawy M, Espehaug B, Indrekvam K, Havelin LI, Furnes O (2014) Higher revision risk for unicompartmental knee arthroplasty in low-volume hospitals. Acta Orthop 85(4):342-347

17. Sanz-Ruiz P, Matas-Diez JA, Carbo-Laso E, Perez-Mananes R, Vaquero-Martin J (2019) Patient-specific instrument can improve functional and radiographic results during learning curve for Oxford Unicompartmental knee Arthroplasty. J Knee Surg 32(2):180-185

18. Jones GG, Clarke S, Jaere M, Cobb J (2018) 3D printing and unicompartmental knee arthroplasty. EFORT Open Rev 3(5):248-253

19. Gong S, Xu W, Wang R, Wang Z, Wang B, Han L, Chen G (2019) Patientspecific instrumentation improved axial alignment of the femoral component, operative time and perioperative blood loss after total knee arthroplasty. Knee Surg Sports Traumatol Arthrosc 27(4):1083-1095

20. Li Z, Yang Z, Liao W, Wang W, Zou Y, Pan Y, Feng Z (2019) Fewer femoral rotational outliers produced with $C T$ - than with MRI-based patient-specific instrumentation in total knee arthroplasty. Knee Surg Sports Traumatol Arthrosc. https://doi.org/10.1007/s00167-019-05678-X

21. Bell SW, Stoddard J, Bennett C, London NJ (2014) Accuracy and early outcomes in medial unicompartmental knee arthroplasty performed using patient specific instrumentation. Knee 21(Suppl 1):S33-S36

22. Dao Trong ML, Diezi C, Goerres G, Helmy N (2015) Improved positioning of the tibial component in unicompartmental knee arthroplasty with patientspecific cutting blocks. Knee Surg Sports Traumatol Arthrosc 23(7):19931998

23. Leon-Munoz VJ, Martinez-Martinez F, Lopez-Lopez M, Santonja-Medina F (2019) Patient-specific instrumentation in total knee arthroplasty. Expert Rev Med Devices 16(7):555-567

24. Alvand A, Khan T, Jenkins C, Rees JL, Jackson WF, Dodd CAF, Murray DW, Price AJ (2018) The impact of patient-specific instrumentation on unicompartmental knee arthroplasty: a prospective randomised controlled study. Knee Surg Sports Traumatol Arthrosc 26(6):1662-1670

25. Kerens B, Schotanus MG, Boonen B, Kort NP (2015) No radiographic difference between patient-specific guiding and conventional Oxford UKA surgery. Knee Surg Sports Traumatol Arthrosc 23(5):1324-1329

26. Ollivier M, Parratte S, Lunebourg A, Viehweger E, Argenson JN (2016) The John Insall award: no functional benefit after Unicompartmental knee Arthroplasty performed with patient-specific instrumentation: a randomized trial. Clin Orthop Relat Res 474(1):60-68

27. Leenders AM, Schotanus MGM, Wind RJP, Borghans RAP, Kort NP (2018) A high rate of tibial plateau fractures after early experience with patientspecific instrumentation for unicompartmental knee arthroplasties. Knee Surg Sports Traumatol Arthrosc 26(11):3491-3498

28. Barbadoro P, Ensini A, Leardini A, d'Amato M, Feliciangeli A, Timoncini A, Amadei F, Belvedere C, Giannini S (2014) Tibial component alignment and risk of loosening in unicompartmental knee arthroplasty: a radiographic and radiostereometric study. Knee Surg Sports Traumatol Arthrosc 22(12):31573162

29. Jones GG, Clarke S, Harris S, Jaere M, Aldalmani T, de Klee P, Cobb JP (2019) A novel patient-specific instrument design can deliver robotic level accuracy in unicompartmental knee arthroplasty. Knee 26(6):1421-1428

30. Batailler C, White N, Ranaldi FM, Neyret P, Servien E, Lustig S (2019) Improved implant position and lower revision rate with robotic-assisted unicompartmental knee arthroplasty. Knee Surg Sports Traumatol Arthrosc. 27(4):1232-1240.

31. Herry Y, Batailler C, Lording T, Servien E, Neyret P, Lustig S (2017). Improved joint-line restitution in unicompartmental knee arthroplasty using a roboticassisted surgical technique. Int Orthop 41(11):2265-2271 
32. Kerens B, Leenders AM, Schotanus MGM, Boonen B, Tuinebreijer WE, Emans PJ, Jong B, Kort NP (2018) Patient-specific instrumentation in Oxford unicompartmental knee arthroplasty is reliable and accurate except for the tibial rotation. Knee Surg Sports Traumatol Arthrosc. 26(6):1823-1830.

33. Seeber GH, Kolbow K, Maus U, Kluge A, Lazovic D (2016) Medial unicompartmental knee arthroplasty using patient-specific instrumentation accuracy of preoperative planning, time saving and cost efficiency. Z Orthop Unfall. 154(3):287-293.

\section{Publisher's Note}

Springer Nature remains neutral with regard to jurisdictional claims in published maps and institutional affiliations.

\section{Submit your manuscript to a SpringerOpen ${ }^{\circ}$ journal and benefit from:}

- Convenient online submission

- Rigorous peer review

- Open access: articles freely available online

- High visibility within the field

- Retaining the copyright to your article

Submit your next manuscript at $\boldsymbol{\nabla}$ springeropen.com 